\title{
Maternal Eating and Physical Activity Strategies and their Relation with Children's Nutritional Status ${ }^{1}$
}

\author{
Yolanda Flores-Peña² \\ Rosario Edith Ortiz-Félix ${ }^{3}$ \\ Velia Margarita Cárdenas-Villarreal ${ }^{2}$ \\ Hermelinda Ávila-Alpirez ${ }^{4}$ \\ Corina Mariela Alba-Alba ${ }^{3}$ \\ Roandy Gaspar Hernández-Carranco ${ }^{3}$
}

Objectives: to describe the maternal eating and physical activity strategies (monitoring, discipline, control, limits and reinforcement) [MEES]; to determine the relation between MEES and the child's nutritional status [body mass index (BMI) and body fat percentage (BFP)]; to verify whether the MEES differ according to the child's nutritional status. Method: participants were 558 mothers and children ( 3 to 11 years of age) who studied at public schools. The Parental Strategies for Eating and Activity Scale (PEAS) was applied and the child's weight, height and BFP were measured. For analysis purposes, descriptive statistics were obtained, using multiple linear regression and the Kruskal-Wallis test. Results: the highest mean score was found for reinforcement (62.72) and the lowest for control (50.07). Discipline, control and limits explained $12 \%$ of the BMI, while discipline and control explained $6 \%$ of the BFP. Greater control is found for obese children $\left(\chi^{2}=38.36, p=0.001\right)$ and greater reinforcement for underweight children $\left(\chi^{2}=7.19, \mathrm{p}<0.05\right)$. Conclusions: the mothers exert greater control (pressure to eat) over obese children and greater recognition (congratulating due to healthy eating) in underweight children. Modifications in parental strategies are recommended with a view to strengthening healthy eating and physical activity habits.

Descriptors: Mothers; Parent-Child Relations; Child Rearing; Obesity; Body Composition; Strategies.

\footnotetext{
${ }^{1}$ Supported by Instituto de Nutrición y Salud Kellogg's.

2 PhD, Full Professor, Facultad de Enfermería, Universidad Autónoma de Nuevo León, Monterrey, Nuevo León, Mexico.

${ }^{3}$ Doctoral students, Facultad de Enfermería, Universidad Autónoma de Nuevo León, Monterrey, Nuevo León, Mexico.

${ }^{4}$ PhD, Full Professor, Unidad Académica Multidisciplinaria, Universidad Autónoma de Tamaulipas, Matamoros, Tamaulipas, Mexico.
}

Corresponding Author:

Yolanda Flores-Peña

Universidad Autónoma de Nuevo León. Facultad de Enfermería Av. Gonzalitos, 1500

Monterrey, Nuevo León, México

E-mail: yflores_mx@yahoo.com.mx
Copyright (c) 2014 Revista Latino-Americana de Enfermagem This is an Open Access article distributed under the terms of the Creative Commons Attribution Non-Commercial License (CC BY-NC).

This license lets others distribute, remix, tweak, and build upon your work non-commercially, and although their new works must also acknowledge you and be non-commercial, they don't have to license their derivative works on the same terms. 


\section{Introduction}

According to the World Health Organization, children and adolescents cannot choose the environment they live in or the food they consume. Therefore, they need special attention in the fight against the obesity epidemic $(\mathrm{OB})^{(1)}$. Mexico presents one of the highest obesity prevalence rates of overweight (OW) - OB around the world, as $34 \%$ of the children younger than five and $32 \%$ of girls and $37 \%$ of boys between 5 and 11 years of age suffer from $\mathrm{OW}-\mathrm{OB}^{(2)}$. This situation indicates the need to explore related and modifiable factors in the attempt to reduce this problem.

According to the literature, the parenthood or upbringing could affect children's eating and physical activity through practices, styles and strategies(3), which have been studied more frequently with regard to eating ${ }^{(4)}$, and not so much with regard to physical activity. Nevertheless, the literature is inconclusive about the concept and measuring of these constructs ${ }^{(5-8)}$, mainly deriving from the parenting type ${ }^{(8)}$.

Most studies about parenting strategies related to eating were developed in the United States ${ }^{(9-12)}$, involving white, African-American and Hispanic mothers. The results regarding the association between parenting styles and children's $\mathrm{OB}^{(4)}$, food intake ${ }^{(9)}$ and body mass index $(\mathrm{BMI})^{(10-11)}$ are inconclusive though. This discrepancy in the results could be attributed to different factors, such as the sociocultural differences among population groups ${ }^{(13)}$.

The parenting strategies related to eating and physical activity have been studied in Latin families living in San Diego, California, and have been described as: monitoring, discipline, control, setting limits and reinforcement. Monitoring was considered as the extent to which the parents supervise their children's healthy conducts, and discipline as how frequently the parents sanction their children for practicing unhealthy eating conducts and involving in sedentary behaviors ${ }^{(10)}$.

Control was defined as the parents' skill or power to have their children do what they want, while limits refer to the extent to which the parents permit their children's unhealthy eating and sedentary behaviors and, finally, reinforcement refers to congratulating the children when they practice healthy conducts. To evaluate the abovementioned strategies, the authors developed the Parental Strategies for Eating and Activity Scale (PEAS) in English and Spanish(10).

Other studies have discussed the concept of parenting styles, conceptualizing style as the balance between the parents' responsibility and their demands on the children. It has been observed that the predominant style among Hispanic parents is authoritarian, marked by high demand/low responsibility, with an association with healthy eating behaviors. The authors highlight, however, that the authoritarian style does not support the child's internalization of the parental values and added that the parents exert more control over younger than over older children ${ }^{(9)}$

It has been described that the Mexican culture emphasizes respect for authority and the use of strict rules to discipline the children. As appointed, MexicanAmerican parents demonstrate a range of styles, in which the authoritarian style could be related with a low educational level and low salaries. Besides the parents' sociodemographic characteristics, the children's characteristics, including the nutritional status, could influence the parents' strategies or, vice-versa, children with OW could negatively respond to the parental control, consuming more calories ${ }^{(14)}$.

Given that the nursing staff occupies a crucial position to provide the parents with education and tools focused on positive parenting, it was considered important to broaden the research to evaluate the parenting strategies associated with OB-related conducts in Mexican families living in the Northeast of Mexico, Understanding this phenomenon will help to develop culturally appropriate programs focused on parents with a view to prevention/intervention in childhood OB. Therefore, this study was undertaken with the following objectives: 1) To describe the maternal eating and physical activity strategies (MEES), 2) To determine the relation between the MEES and the child's nutritional status [(BMI) and body fat percentage (BFP)] and 3) To verify whether the MEES differ according to the child's nutritional status in Mexican mothers living in the Northeast of that country.

\section{Methods}

\section{Design and Participants}

Cross-sectional study. The population consisted of 754 mother-child dyads who lived in the state of Nuevo León, in the Northeast of Mexico, where industrial activities are predominant. The children studied in four public educational institutions (two preschools and two schools) in the metropolitan area of Monterrey, the state capital of Nuevo León. At these schools, 379 male and 375 female students were registered, who were between 3 and 11 years of age. 
The schools were randomly selected from the list of the Secretary of Public Education and contacted, when the boards were asked to authorize the research. A written message was sent to the mother's home through the child, in which she was invited to participate and the objectives, procedures, dates and times were mentioned when she could participate.

The following inclusion criteria were considered: the participant mothers should verbally declare themselves as the minors' mothers, mothers and children should have been born in Mexico and the mothers should allow to have theirs and their children's anthropometric measures taken. The inclusion criteria for the children were: allowing to have their anthropometric measures taken, while the mother mentioning that her child suffered from a disease that could affect his/her growth and development, such as diabetes, renal or cardiac disease, was considered as an exclusion criterion.

\section{Measures}

To assess the MEES, the PEAS(10) scale was used in Spanish. Permission was obtained from the authors for application in the present study (available upon request only). The scale consists of 26 items, 16 of which evaluate the eating strategies, using a Likert scale ranging from 1 , which indicates that the mother never uses the strategy, to 5, indicating that she uses it frequently; the other 10 items evaluate the activity strategies, in which 1 represents disagreement and 5 agreement.

The responses are grouped in five factors: Setting limits with 6 responses, for example: I limit how long my son/daughter watches TV or videos on weekdays, with scores ranging from 6 to 30 (higher scores indicating greater limits on unhealthy eating and sedentary activities), Monitoring with 7 responses, for example: How frequently do you supervise how long your child watches TV or videos on weekdays? Scores range between 7 and 35 (higher scores indicating greater monitoring of unhealthy eating and sedentary activities), Discipline with 5 responses, for example: How frequently do you discipline your child for playing videogames or using the computer without asking permission? Scores range between 5 and 25 (higher scores indicating greater discipline of unhealthy eating and sedentary activities), Control with 6 responses, for example: I make sure my child eats everything even if (s)he says that (s)he's not hungry, with scores ranging between 6 and 36 (higher scores indicating greater pressure towards unhealthy eating and sedentary activities), Reinforcement with
2 responses, for example: How frequently do you congratulate your child for having eaten a healthy snack? Scores range between 2 and 10 (higher scores indicating congratulations for healthy eating and physical activity). In this study, the reliability of the PEAS scale as indicated by Cronbach's alpha corresponded to 0.84 , in line with the findings of the study that involved Latin mothers living in the United States ${ }^{(10,12)}$.

In addition, the mothers' sociodemographic data were obtained, including aging, education in years, occupation, marital status, family income and place of birth. The following information was requested from the children: date and place of birth, age and sex.

The BMI and BFP were used as indicators of the child's nutritional status. Height was measured with the help of a SECA 214 stadiometer, approximated to $0.1 \mathrm{~cm}$; weight was measured using Seca 813 scales with a capacity of 200 kilograms and a precision level of $0.1 \mathrm{gr}$. Both procedures were accomplished with the participants standing barefoot. Next, the BMi was calculated by applying the formula weight/height ${ }^{2}$ and was classified as followed according to the percentage: Malnutrition (percentile $<3$ ), Underweight ( $\geq 3$ and $<15$ ), Normal weight ( $\geq 15$ and $<85$ ), OW ( $\geq 85$ but $<97)$ and OB $(\geq 97)^{(15)}$. The BFP was measured through bioelectric impedance with the help of Inbody 230 equipment.

To collect the information, the mother signed the informed consent form and answered the PEAS scale at the child's schools. Mothers who were unavailable at preset times were located through home visits (up to two visits). Trained and standardized personnel collected the weight, height and BFP measures of the children at the schools.

This research received approval from the Ethics Committee at the School of Nursing of UANL (FAEN-P-740) and complied with the Regulations of the General Health Law for Health Research of the Mexican Secretary of Health.

\section{Data Analysis}

The data were collected and analyzed using the statistical software Statistical Package for the Social Sciences (SPSS), version 20.0 for Windows. The scores for each factor of the PEAS were transformed into rates from 0 to 100 and descriptive statistics were calculated.

Two multiple linear regression analyses were applied, one to determine the relation between the child's MEES and BMI and the other between the child's MEES and BFP. Hence, the independent variable MEES 
was the score for each of the five factors of the PEAS scale (setting limits, monitoring, discipline, control and reinforcement) and the dependent variables were the BMI and BFP results. In addition, the variance inflation factors were obtained to check the co-linearity of existing problems between the independent variables.

Finally, the Kruskal-Wallis test was applied to check for differences between the MEES (scores obtained on the PEAS factors) according to the child's nutritional status (malnutrition, underweight, normal, OW and $\mathrm{OB}$ ). Statistical significance was set at $p<.05$.

\section{Results}

Participants were 558 dyads (mother-child). The maternal age varied between 19 and 53 years, with a mean age of 34.37 years $(S D=6.90)$. In terms of education, the participants had an average 12.52 years $(S D=3.28)$ of schooling. In addition, $75.30 \%$ of the mothers were married, $52.70 \%$ were housewives and $47.13 \%$ had a paid job, mostly in the informal market. The participants indicated a mean family income of $\$ 680.00$ USD (SD=475.00).

Concerning the children, the ages ranged between 3 and 11 years, with a mean age of 7.38 years $(S D=2.55)$. Girls corresponded to $50.54 \%(\mathrm{~N}=282)$ and boys to $49.46(\mathrm{~N}=276)$. According to the weight category, $3.05 \%(\mathrm{~N}=17)$ of the children were underweight, $59.32 \%(\mathrm{~N}=331)$ normal weight, $16.30 \%(\mathrm{~N}=91)$ OW and $21.33 \%(\mathrm{~N}=119) \mathrm{OB}$. The mean BFP of the male participants was $26.30(S D=10.07)$ and that of the female participants was $27.12(\mathrm{SD}=8.15)$.

According to objective 1 , among the five factors, the highest mean score was found for reinforcement (62.72) and the lowest for control (50.07). These data are shown in Table 1

Table 1 - Descriptive statistics of factors of the Parenting strategies for Eating and Activity Scale (PEAS), Monterrey, Nuevo León, Mexico, 2011

\begin{tabular}{|c|c|c|}
\hline Factors & $\bar{\chi}$ & $S D$ \\
\hline Monitoring & 51.23 & 21.20 \\
\hline Discipline & 54.21 & 22.12 \\
\hline Control & 50.07 & 19.44 \\
\hline Limits & 56.27 & 24.94 \\
\hline Reinforcement & 62.72 & 26.32 \\
\hline
\end{tabular}

In the first regression analysis, using the Enter procedure with manual elimination of variables, it was identified that limits, control and discipline explained $12 \%$ of the variance in the children's BMI $\left(F_{(3,554)}=25.44, p=.001, R^{2}=0.12\right)$. Specifically, it is shown that these variables predict higher $\mathrm{BMI}$ scores. The variance inflation factor demonstrate that there is no co-linearity among the independent variables (Table 2).

In the second regression analysis (Table 3), a two-factor model was identified: control and discipline explained $6 \%$ of the variance in the child's BFP $\left(F_{(2,553)}=19.86, p=0.001, R^{2}=0.06\right)$. Specifically, it is shown that these variables predict a higher BFP. Like in the previous model, no co-linearity was identified among the independent variables in accordance with the variance inflation factor (Table 3 ).

Table 2 - Regression model between Maternal Eating and Activity Strategies (MEES) and the child's Body Mass Index (BMI), Monterrey, Nuevo León, Mexico, 2011

\begin{tabular}{|c|c|c|c|c|c|c|c|c|}
\hline \multirow{2}{*}{ Variable } & \multirow{2}{*}{$\begin{array}{c}\text { Non- } \\
\text { standardized } \beta\end{array}$} & \multirow{2}{*}{$\begin{array}{l}\text { Standard } \\
\text { error }\end{array}$} & \multirow{2}{*}{ Standardized $\beta$} & \multirow{2}{*}{ T-value } & \multirow{2}{*}{$\begin{array}{c}\text { Variance } \\
\text { Inflation Factor }\end{array}$} & \multicolumn{2}{|c|}{$95 \% \mathrm{Cl}$} & \multirow{2}{*}{$\mathbf{p}$} \\
\hline & & & & & & Lower Limit & Upper Limit & \\
\hline Constant & 13.24 & 0.600 & & 21.81 & & & & 0.001 \\
\hline Discipline & 0.015 & 0.007 & 0.101 & 2.22 & 1.154 & 0.002 & 0.029 & 0.026 \\
\hline Control & 0.061 & 0.007 & 0.332 & 8.24 & 1.021 & 0.046 & 0.075 & 0.001 \\
\hline Limits & 0.014 & 0.006 & 0.095 & 2.35 & 1.150 & 0.002 & 0.026 & 0.019 \\
\hline
\end{tabular}

Table 3 - Regression model between MEES and the child's Body Fat Percentage (BFP), Monterrey, Nuevo León, Mexico, 2011

\begin{tabular}{|c|c|c|c|c|c|c|c|c|}
\hline \multirow{2}{*}{ Factor } & \multirow{2}{*}{$\begin{array}{c}\text { Non- } \\
\text { standardized } \beta\end{array}$} & \multirow{2}{*}{$\begin{array}{l}\text { Standard } \\
\text { error }\end{array}$} & \multirow{2}{*}{ Standardized $\beta$} & \multirow{2}{*}{ t-value } & \multirow{2}{*}{$\begin{array}{c}\text { Variance } \\
\text { Inflation Factor }\end{array}$} & \multicolumn{2}{|c|}{$95 \% \mathrm{Cl}$} & \multirow{2}{*}{$\mathbf{p}$} \\
\hline & & & & & & Lower Limit & Upper Limit & \\
\hline Constant & 18.810 & 1.474 & & 12.75 & & & & 0.001 \\
\hline Discipline & 0.035 & 0.017 & 0.084 & 2.04 & 1.016 & 0.001 & 0.069 & 0.042 \\
\hline Control & 0.120 & 0.019 & 0.255 & 6.17 & 1.016 & 0.082 & 0.158 & 0.001 \\
\hline
\end{tabular}


Finally, through the Kruskal-Wallis test, a significant difference in the control and reinforcement factors was found according to the child's nutritional status. The mothers are more controlling in children with OB $\left(\chi^{2}=38.36, p<0.001\right)$ and more reinforcing in underweight children $\left(\chi^{2}=7.19, p<0.05\right)$. The data are presented in Table 4.

Table 4 - Kruskal-Wallis test of MEES according to the child's nutritional status, Monterrey, Nuevo León, Mexico, 2011

\begin{tabular}{|c|c|c|c|c|c|c|c|c|c|c|c|c|}
\hline \multirow{5}{*}{ Strategy } & \multicolumn{12}{|c|}{ Child's Nutritional Status } \\
\hline & \multicolumn{3}{|c|}{ Low } & \multicolumn{3}{|c|}{ Normal } & \multicolumn{3}{|c|}{ Overweight } & \multirow{2}{*}{\multicolumn{3}{|c|}{$\begin{array}{l}\text { Obesity } \\
\mathrm{N}=119\end{array}$}} \\
\hline & \multicolumn{3}{|c|}{$\mathrm{N}=17$} & \multicolumn{3}{|c|}{$\mathrm{N}=331$} & \multicolumn{3}{|c|}{$\mathrm{N}=91$} & & & \\
\hline & \multirow{2}{*}{$\bar{\chi}$} & \multicolumn{2}{|c|}{$95 \% \mathrm{Cl}$} & \multirow{2}{*}{$\bar{\chi}$} & \multicolumn{2}{|c|}{$95 \% \mathrm{Cl}$} & \multirow{2}{*}{$\bar{\chi}$} & \multicolumn{2}{|c|}{$95 \% \mathrm{Cl}$} & \multicolumn{3}{|c|}{$95 \% \mathrm{Cl}$} \\
\hline & & $\mathrm{LL}^{*}$ & $\mathrm{UL}^{\dagger}$ & & $\mathrm{LL}^{*}$ & $\mathrm{UL}^{\dagger}$ & & LL* $^{*}$ & $\mathrm{UL}^{\dagger}$ & $\bar{\chi}$ & LL* $^{*}$ & $\mathrm{UL}^{\dagger}$ \\
\hline Monitoring & 52.94 & 42.61 & 63.27 & 50.76 & 48.46 & 53.07 & 50.62 & 46.71 & 54.53 & 52.76 & 48.60 & 59.61 \\
\hline Discipline & 49.85 & 35.95 & 63.74 & 52.63 & 50.19 & 55.07 & 58.14 & 53.93 & 62.35 & 56.21 & 52.35 & 60.06 \\
\hline Control & 37.25 & 27.93 & 46.57 & 47.40 & 45.31 & 49.49 & 50.59 & 46.47 & 54.71 & 58.92 & 55.92 & 61.93 \\
\hline Limits & 63.23 & 50.64 & 75.82 & 56.18 & 53.41 & 58.94 & 56.08 & 50.86 & 61.30 & 55.70 & 51.46 & 59.94 \\
\hline Reinforcement & 74.26 & 63.49 & 85.03 & 63.36 & 60.52 & 66.21 & 64.01 & 58.82 & 69.20 & 58.29 & 53.29 & 63.29 \\
\hline
\end{tabular}

*LL: Lower Limit

+UL: Upper Limit

\section{Discussion}

In the description of the MEES, it was identified that reinforcement was the strategy the Mexican mothers mentioned most, which is focused on congratulating the children when they practice healthy behaviors. On the other hand, the lowest score was found for the control strategy, which refers to the pressure the mothers exert for the children not to adopt unhealthy eating conducts and sedentary activities. The PEAS scale was applied, which until the termination date of the literature review was the only instrument to assess the reinforcement strategy; this scale has been applied in studies involving Latin mothers in the United States, in which no information is provided about the mean MEES scores $^{(10,12)}$.

The highest score for the reinforcement strategy may be due to the trend to give affirmative answers to questions related to positive parenting strategies. On the other hand, the authors of the PEAS scale signaled the fact that only two items are included to evaluate the reinforcement strategy as a limit, which could cause its inappropriate measuring(10).

As mentioned, the lowest score was found for the control strategy. Nevertheless, a positive and significant relation was identified between this strategy and the child's nutritional status (BMI and BFP), used to verify objective two. In this regard, it has been observed that control plays an important role in the development of children's eating preferences and has been associated with unhealthy eating and activity conducts. In addition, control can prevent children from developing the capacity to regulate their own food intake and appetite when alone, which could put them at greater risk of developing $\mathrm{OB}^{(4)}$. Research findings are inconsistent though. On the one hand, it has been observed that parents who use more control strategies have children with a lower BMI, related to preschool children ${ }^{(10)}$.

In another study, which involved Latin mothers, it was found that they tend to exert greater control over their children's conducts, which could be influenced by different factors, such as concerns with their children having self-esteem problems in case of OW. Nevertheless, independently of the mothers' motives, the results indicate that the control styles are counterproductive and can contribute to the risk of $\mathrm{OW}-\mathrm{OB}^{(16)}$.

Two strategies that were also associated with the children's nutritional status were limits and discipline. In this respect, the evidence indicates that demanding parents' imposition of rules can provoke sedentary conducts in the children(17) and also alter their internal hunger and satiety mechanisms ${ }^{(18)}$, all the more when considering that these strategies distinguish the authoritarian parental style, which is predominant in Mexican parents, characterizing by the exercise of control as manipulation of the child's feelings and bonding, without limits and strict rules, which could increase the calorie and fat intake ${ }^{(19)}$ and, therefore, the BMI levels.

In that sense, it has been described that the parental use of covert control (limiting the availability of tasty appetizers at home for example) in comparison with manifest control (setting standards for the intake of food available at home) could help to select healthy 
foods and permit the child's independence with regard to decisions about food and eating(14). Finally, it was found that the mothers are more controlling towards children with $\mathrm{OB}$. This finding is extremely important, as one of the control strategies is the pressure to eat, which could aggravate the weight problem even further.

As mentioned, studies that applied the PEAS scale $^{(9,20)}$ have used the child's BMI as an indicator. In our study, the BMI and BFP were used as indicators of the child's nutritional status, the latter measured through bioelectric impedance. In this respect, a BFP of $26.3 \%$ was found for boys and $27.1 \%$ for girls. It should be observed that, until the termination date of the literature review, no studies undertaken in Mexico were found that registered the BFP levels in childhood populations.

One finding of interest is that almost half of the participating mothers had a paid job, mostly in the informal market, leading to the supposition that other people are in charge of the children's care and upbringing, an aspect that was not assessed in this study. When the mother goes out to work, however, the family's income level puts them in a lower-middle social class, a situation that is also related to an authoritarian parental style(21).

As positive parenting strategies promote the children's development, trust and self-esteem, the parents need further training on these strategies. Therefore, it is relevant for the nursing staff to identify the areas of opportunity that permits the design and implementation of intervention programs adapted to the parents' needs. This represents a strong point in this study, which permitted a first approximation of the parenting strategies related to children's nutritional status in Mexican mothers.

Considering the finding that control differs according to the child's nutritional status and that pressure to

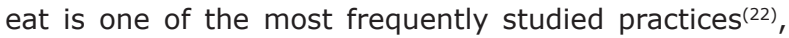
which appears as a control strategy in the PEAS, with differences in line with the child's age, further research on this strategy is recommended. In addition, the psychometric properties of the PEAS should be evaluated in Mexican mothers, besides broadening and focusing the analysis of each of the MEES and its relation with other variables, such as age, sex of the child, maternal education and income and other maternal cognitive factors, such as the mothers' perception of and concern with the children's weight, variables that have been indicated as mediators between the children's nutritional status and the mothers' eating styles ${ }^{(22)}$.
Also, other family members and/or caregivers involved in the children's upbringing while the mothers go out to work need to be considered, as well as the use of other instrument to characterize the upbringing styles according to parenting types.

The present findings suggest that the maternal eating and exercise strategies: control, limits and discipline are associated with the children's BMI and BFP, that the mothers are more controlling over children with $\mathrm{OB}$ and more reinforcing for underweight children. Therefore, interventions are required to educate and train the parents with a view to the practice of positive parenting strategies that permit the promotion of healthy eating and physical activity.

\section{References}

1. Organización Mundial de la Salud [Internet]. Estrategia mundial sobre régimen alimentario, actividad física y salud. Sobrepeso y obesidad infantiles. [acesso 27 jun 2009]; 2013. Disponível em: http://www.who. int/dietphysicalactivity/childhood/es/

2. Gutiérrez JP, Rivera-Dommarco J, Shamah-Levy T, Villalpando-Hernández S, Franco A, Cuevas-Nasu L, et al. Encuesta Nacional de Salud y Nutrición 2012. Resultados Nacionales. Cuernavaca, México: Instituto Nacional de Salud Pública; 2012.

3. Ventura AK, Birch LL. Does parenting affect children's eating and weight status? Int J Behav Nutr Phys Act. 2008;5:15.

4. Olvera N, Power TG. Brief report: parenting styles and obesity in Mexican American children: a longitudinal study. J Pediatr Psychol. 2010;35(3):243-9.

5. Vaughn AE, Tabak RG, Bryant MJ, Ward DS. Measuring parent food practices: a systematic review of existing measures and examination of instruments. Int J Behav Nutr Phys Act. 2013;10:61.

6. de Lauzon-Guillain B, Oliveira A, Charles MA, Grammatikaki $E$, Jones $L$, Rigal $N$, et al. A review of methods to assess parental feeding practices and preschool children's eating behavior: the need for further development of tools. J Acad Nutr Diet. 2012;112(10):1578-602.

7. Lopes MSOC, Dixe MACR. Positive parenting by parents of children up to three years of age: development and validation of measurement scales. Rev. Latino-Am. Enfermagem. 2012;20(4):787-95.

8. Macarini SM, Martins G Dal Forno, Minetto MFJ, Vieira ML. Práticas parentais: uma revisão da literatura brasileira. Arq Bras Psicol. [Internet]. 2010 
[acesso 16 out 2013]; 62(1):119-34. Disponível em: http://pepsic.bvsalud.org/scielo.php?script $=$ sci_ arttext\&pid=S1809-52672010000100013\&lng=pt

9. Hoerr SL, Hughes SO, Fisher JO, Nicklas TA, Liu Y, Shewchuk RM. Associations among parental feeding styles and children's food intake in families with limited incomes. Int J Behav Nutr Phys Act. 2009 Aug 13;6:55.

10. Larios SE, Ayala GX, Arredondo EM, Baquero B, Elder JP. Development and validation of a scale to measure Latino parenting strategies related to children's obesigenic behaviors. The parenting strategies for eating and activity scale (PEAS). Appetite. 2009 Feb;52(1):166-72.

11. Tovar A, Hennessy E, Pirie A, Must A, Gute DM, Hyatt $R R$, et al. Feeding styles and child weight status among recent immigrant mother-child dyads. Int J Behav Nutr Phys Act. 2012 May 29;9:62.

12. Ayala GX, Elder JP, Campbell NR, Arredondo E, Baquero B, Crespo NC, Slymen DJ. Longitudinal intervention effects on parenting of the Aventuras para Niños study. Am J Prev Med. 2010 Feb;38(2):154-62.

13. Huang SH, Parks EP, Kumanyika SK, Grier SA, Shults

J, Stallings VA, Stettler N. Child-feeding practices among Chinese-American and non-Hispanic white caregivers. Appetite. 2012 Jun;58(3):922-7.

14. Ogden J, Reynolds R, Smith A. Expanding the concept of parental control: a role for overt and covert control in children's snacking behaviour? Appetite 2006; 47:100-6.

15. World Health Organization. Software for assessing growth of the world's children and adolescents [Internet]. [acesso 14 jan 2012]; Disponível em: http:// www.who.int/growthref/tools/en/

16. Olvera-Ezzell N, Power TG, Cousins JH. Maternal socialization of children's eating habits: strategies used by obese Mexican-American mothers. Child Dev. 1990 Apr;61(2):395-400.

17. Schneider EM, Wilson DK, Kitzman-Ulrich $H$, George SM, Alia KA. The associations of parenting factors with adolescent body mass index in an underserved population. J Obes. 2013;2013:715618.

18. Lindsay AC, Sussner KM, Greaney ML, Peterson KE. Latina mothers' beliefs and practices related to weight status, feeding, and the development of child overweight. Public Health Nurs. 2011 Mar-Apr;28(2):107-18.

19. Kim MJ, McIntosh WA, Anding J, Kubena KS, Reed DB, Moon GS. Perceived parenting behaviours predict young adolescents' nutritional intake and body fatness. Matern Child Nutr. 2008 Oct;4(4):287-303.
20. Crespo NC, Elder JP, Ayala GX, Slymen DJ, Campbell $\mathrm{NR}$, Sallis JF, et al. Results of a multi-level intervention to prevent and control childhood obesity among Latino children: the Aventuras Para Niños Study. Ann Behav Med. 2012 Feb;43(1):84-100.

21. Varela R, Vernberg EM, Sanchez-Sosa Jj et al. Parenting style of Mexican, Mexican American, and Caucasian-Non- Hispanic families: social context and cultural influences. J Fam Psychol 2004;18:651-7.

22. Webber L, Hill C, Cooke L, Carnell S, Wardle J. Associations between child weight and maternal feeding styles are mediated by maternal perceptions and concerns. Eur J Clin Nutr. 2010 Mar;64(3):259-65. 